\title{
KENDALI OPTIMAL PERTUMBUHAN POPULASI ECENG GONDOK DENGAN IKAN GRASS CRAP DAN PEMANENAN
}

\author{
Fitroh Resmi \\ Aris Alfan \\ Slamet Ifandi \\ FMIPA Universitas Billfath \\ e-mail: fitroh.resmi@billfath.ac.id
}

\begin{abstract}
Water hyacinth is a wild aquatic plant that grows quickly. The growth of water hyacinth need to be controled to prevent the flood and not to disturb paddy irrigation channels. Grass carp as herbivorous fish is used as natural predator to reduce the population of water hyacinth. The interaction between water hyacinth and grass carp is modeled using the prey-predator system. In this model there are harvest factors and predation factors using Holling type III. The optimal control problem is applied to minimize the mass of water hyacinth and harvest efforts of water hyacinth and maximize the mass of grass carp. The solution uses the Pontryagin Principle. The result is that the harvesting of water hyacinth and the grass carp can minimize the water hyacinth biomass at the end of time.
\end{abstract}

Keywords: eceng gondok, grass carp, harvesting, pontryagin, optimal control

\begin{abstract}
ABSTRAK
Eceng gondok merupakan tanaman liar di perairan yang tumbuh dengan cepat. Pertumbuhannya perlu dikendalikan agar tidak menyebabkan banjir dan tidak mengganggu saluran irigasi persawahan. Ikan grass carp sebagai ikan herbivora digunakan sebagai predator alami untuk mengurangi populasi eceng gondok. Hubungan antara eceng gondok dan ikan grass carp dimodelkan dengan menggunakan sistem prey-predator. Pada model ini terdapat faktor pemanenan dan faktor predasi menggunakan Holling tipe III. Masalah kendali optimal diterapkan dengan tujuan untuk meminimumkan massa eceng gondok dan usaha pemanenan eceng gondok serta memaksimumkan massa ikan grass carp. Penyelesaiannya menggunakan Prinsip Pontryagin. Hasilnya dengan adanya usaha pemanenan eceng gondok dan pengadaan ikan grass carp dapat meminimumkan biomassa eceng gondok di waktu akhir.
\end{abstract}

Kata kunci: eceng gondok, grass carp, pemanenan, pontryagin, kendali optimal

Eceng gondok merupakan tanaman liar yang umumnya hidup di daerah perairan. Pertumbuhannya yang cepat dapat mencapai 3\% per hari (Naji'ah \& Nurul, 2016). Tingkat pertumbuhannya dapat mencapai $100 \%$ luas dalam waktu hanya dua minggu (Kementrian Lingkungan Hidup Republik Indonesia, 2014). Perkembangan tanaman air ini akan menghambat pertumbuhan fitoplankton sehingga memperkecil persediaan pakan bagi jenis ikan tertentu (Kementrian Kelautan dan Perikanan, 2014). Selain itu, juga dapat mengakibatkan banjir dan 
mengganggu saluran irigasi persawahan karena eceng gondok dapat menghambat aliran sungai. Oleh karena itu eceng gondok (Eichornia crassipes) perlu dikendalikan.

Untuk mengendalikan pertumbuhan eceng gondok bisa dilakukan dengan pengambilan secara langsung (pemanenan) atau dengan cara menggunakan predator alaminya. Predator alami yang dimaksud adalah ikan grass carp (Ctenopharyngodon idella) yang merupakan ikan herbivora yang dapat memakan tumbuhan air seperti eceng gondok. Di Jambi telah berhasil menggunakan ikan grass carp untuk membersihkan eceng gondok dari perairan Danau Kerinci dalam waktu 3 tahun (1995-1998) (Kementerian Lingkungan Hidup Republik Indonesia, 2014). Namun 3 tahun bukanlah waktu yang sebentar, sehingga diperlukan kombinasi antara penggunaan ikan grass carp dengan pemanenan eceng gondok.

Pemanenan eceng gondok memerlukan biaya yang tidak sedikit. Hal ini terjadi karena pemanenan eceng gondok berlangsung terus menerus. Selain itu, ikan grass carp membutuhkan eceng gondok sebagai pakannya. Sehingga perlu perhitungan yang tepat mengenai seberapa besar pemanenan yang dilakukan agar dapat meminimumkan biaya pemanenan serta meminimumkan massa eceng gondok sekaligus dapat memaksimumkan massa ikan grass carp. Dalam penelitian ini digunakan teori kendali optimal untuk menentukan besarnya pemanenan yang dilakukan agar dapat mencapai tujuan yang diinginkan.

Penelitian tentang eceng gondok dan ikan grass carp telah banyak dilakukan, seperti yang dilakukan oleh IImiawan, Carnawi, Novanda, Rifki, \& Muhammad (2016) tentang Analisis Dinamik Model Predator-Prey pada Penyebaran Grass Carp sebagai Biokontrol Populasi Eceng Gondok di Perairan Rawapening. Dalam jurnal tersebut sistem dinamik antara eceng gondok, ikan grass carp, dan burung predator dimodelkan dalam sistem prey predator. Hasil analisa kestabilan menyatakan bahwa sistem stabil dalam empat keadaan dengan syarat tertentu yaitu keadaan pertama dimana ketiganya punah, keadaan kedua dimana hanya eceng gondok yang eksis, keadaan ketiga dimana hanya burung predator yang punah, dan keadaan keempat dimana ketiganya eksis. Dari hasil tersebut terlihat bahwa eksistensi ikan grass carp bergantung pada eksistensi eceng gondok. Sehingga pada penlitian ini tujuan utamanya bukan untuk memusnahkan eceng gondok, tapi hanya untuk meminimumkan massa eceng gondok agar dapat mengambil manfaat dari banyaknya ikan grass carp yang hidup.

\section{METODE}

Metode yang digunakan untuk menyelesaikan masalah kendali optimal ada 3 tahapan, yaitu: (Naidu, 2002)

1. Menentukan fungsi tujuan dan sistem dinamik (model matematika dari permasalahan yang akan diselesaikan).

2. Menentukan kondisi batas dan konstrain fisik pada keadaan (state) dan/atau kontrol.

3. Menyelesaikan masalah kendali optimal dengan prinsip maksimum Pontryagin.

Berikut ini adalah langkah-langkahnya:

a. Bentuk Hamiltonian:

$$
H\left(x(t), y(t), e_{1}(t), \lambda_{1}(t), \lambda_{2}(t)\right)=V\left(x(t), y(t), e_{1}(t), t\right)+\lambda^{\prime}(t) f\left(x(t), y(t), e_{1}(t), t\right)
$$


Memaksimumkan $H$ terhadap $e_{1}(t)$, yaitu dengan cara:

$$
\frac{\partial H}{\partial e_{1}}=0
$$

b. Dengan menggunakan $e_{1}{ }^{*}(t)$ yang telah dihasilkan pada langkah $\mathrm{b}$, akan didapatkan fungsi Hamilton baru yang optimal, $H^{*}(t)$.

c. Selesaikan persamaan state dan costate.

\section{HASIL DAN PEMBAHASAN}

Hubungan antara eceng gondok dan ikan grass carp dimodelkan dalam sistem preypredator. Dalam membuat model matematikanya ada beberapa asumsi yang digunakan, yaitu:

a. Pertumbuhan eceng gondok diasumsikan secara logistik.

b. Ikan grass carp hanya memakan eceng gondok

c. Predasi ikan grass carp terhadap eceng gondok menggunakan fungsi respon Holling Tipe III.

d. Terdapat faktor pemanenan terhadap eceng gondok ataupun grass carp.

Berdasarkan asumsi tersebut, model matematika yang dapat dibentuk adalah:

$$
\begin{aligned}
& \frac{d x}{d t}=r x\left(1-\frac{x}{k}\right)-\frac{\alpha x^{2} y}{a^{2}+x^{2}}-e_{1} x \\
& \frac{d y}{d t}=\frac{\alpha x^{2} y}{a^{2}+x^{2}}-m y-e_{2} y
\end{aligned}
$$

dengan:

$x=$ kepadatan biomassa eceng gondok pada saat waktu $t$

$y=$ kepadatan biomassa ikan grass carp pada saat waktu $\mathrm{t}$

$r=$ laju pertumbuhan intrinsik eceng gondok

$k$ = daya dukung lingkungan terhadap eceng gondok

$\alpha=$ laju predasi lkan grass carp terhadap eceng gondok

$\mathrm{a}=$ tingkat kejenuhan ikan grass carp memangsa eceng gondok

$m$ = laju kematian alami ikan grass carp

$e_{1}=$ laju pemanenan pada eceng gondok

$e_{2}=$ laju pemanenan pada ikan grass carp

Dengan kendala berupa model matematika dari pertumbuhan eceng gondok dan ikan grass carp tersebut akan meminimumkan biomassa eceng gondok dan memaksimumkan biomassa ikan grass carp di waktu akhir serta meminimumkan usaha pemanenan eceng gondok selama waktu tertentu. Pemanenan terhadap eceng gondok menjadi kendali yang akan dioptimalkan. Secara matematika dapat dituliskan sebagai berikut.

$$
J\left(e_{1}\right)=-w_{1} x(T)+w_{2} y(T)-w_{3} \int_{0}^{T} e_{1}^{2} d t
$$


dengan:

$\omega_{1}=$ bobot massa eceng gondok saat waktu tertentu

$\omega_{2}=$ bobot massa ikan grass carp saat waktu tertentu

$\omega_{3}=$ bobot fungsi biaya sepanjang interval $T$

$x(T)=$ populasi eceng gondok pada saat waktu tertentu

$y(T)=$ populasi ikan grass carp pada saat waktu tertentu

Nilai awal dan nilai batas sesuai dengan hasil analisa kestabilan yang telah dilakukan oleh peneliti terdahulu (IImiawan, et al, 2016), sehingga nilai kendalinya juga terbatas. Secara matematika dituliskan sebagai berikut.

$$
\begin{aligned}
& x(0)=x_{0}, y(0)=y_{0}, \\
& e_{1_{\text {min }}} \leq e_{1}(t) \leq e_{1_{\text {max }} .}
\end{aligned}
$$

Penyelesaian kendali optimal dengan prinsip maksimum Pontryagin:

1. Membentuk Hamiltonian:

$$
\begin{aligned}
H\left(x(t), y(t), e_{1}(t), \lambda_{1}(t), \lambda_{2}(t)\right)= & -w_{3} e_{1}{ }^{2}+\lambda_{1}\left(r x\left(1-\frac{x}{k}\right)-\frac{\alpha x^{2} y}{a^{2}+x^{2}}-e_{1} x\right) \\
& +\lambda_{2}\left(\frac{\alpha x^{2} y}{a^{2}+x^{2}}-m y-e_{2} y\right)
\end{aligned}
$$

2. Mendapatkan kendali optimal

$$
e_{1}^{*}(t)=\frac{-\lambda_{1} x}{2 w_{3}}
$$

Karena kendalinya terbatas maka:

$$
e_{1}^{*}(t)= \begin{cases}e_{1 \text { min },} & \text { jika } \frac{\partial H}{\partial e_{1}}>0 \\ \frac{-\lambda_{1} x}{2 w_{3}}, & \text { jika } \frac{\partial H}{\partial e_{1}}=0 \\ e_{1_{\text {max }},} & \text { jika } \frac{\partial H}{\partial e_{1}}<0\end{cases}
$$

3. Menyelesaikan persamaan state dan costate

Persamaan state:

$$
\begin{aligned}
& \dot{x}(t)=\frac{\partial H^{*}}{\partial \lambda_{1}}=r x\left(1-\frac{x}{k}\right)-\frac{\alpha x^{2} y}{a^{2}+x^{2}}+\frac{\lambda_{1} x^{2}}{2 w_{3}}=r x\left(1-\frac{x}{k}\right)-\frac{\alpha x^{2} y}{a^{2}+x^{2}}-e_{1} x \\
& \dot{y}(t)=\frac{\partial H^{*}}{\partial \lambda_{2}}=\frac{\alpha x^{2} y}{a^{2}+x^{2}}-m y-e_{2} y
\end{aligned}
$$




\section{Persamaan costate:}

$$
\begin{aligned}
\dot{\lambda}_{1}(t) & =-\frac{\partial H^{*}}{\partial x}=-\left(-\frac{\lambda_{1}{ }^{2} x}{2 w_{3}}+\lambda_{1}\left(r-\frac{2 r x}{k}+\frac{\lambda_{1} x}{w_{3}}\right)-\left(\lambda_{1}-\lambda_{2}\right)\left(\frac{2 \alpha x y a^{2}}{\left(a^{2}+x^{2}\right)^{2}}\right)\right) \\
& =\frac{\lambda_{1}{ }^{2} x}{2 w_{3}}-\lambda_{1}\left(r-\frac{2 r x}{k}+\frac{\lambda_{1} x}{w_{3}}\right)+\left(\lambda_{1}-\lambda_{2}\right)\left(\frac{2 \alpha x y a^{2}}{\left(a^{2}+x^{2}\right)^{2}}\right) \\
& =-\lambda_{1} e_{1}-\lambda_{1}\left(r-\frac{2 r x}{k}-2 e_{1}\right)+\left(\lambda_{1}-\lambda_{2}\right)\left(\frac{2 \alpha x y a^{2}}{\left(a^{2}+x^{2}\right)^{2}}\right) \\
& =-\lambda_{1}\left(r-\frac{2 r x}{k}-e_{1}\right)+\left(\lambda_{1}-\lambda_{2}\right)\left(\frac{2 \alpha x y a^{2}}{\left(a^{2}+x^{2}\right)^{2}}\right) \\
\dot{\lambda}_{2}(t) & =-\frac{\partial H^{*}}{\partial y}=-\left(\left(-\lambda_{1}+\lambda_{2}\right)\left(\frac{\alpha x^{2}}{a^{2}+x^{2}}\right)-\lambda_{2}\left(m+e_{2}\right)\right) \\
& =\left(\lambda_{1}-\lambda_{2}\right)\left(\frac{\alpha x^{2}}{a^{2}+x^{2}}\right)+\lambda_{2}\left(m+e_{2}\right)
\end{aligned}
$$

Dengan kondisi batas yang diberikan oleh keadaan awal dan keadaan akhir yang disebut kondisi transversality. Karena sistem memiliki fix di waktu akhir dan free pada state akhir maka kondisi transversalitynya:

$$
\begin{aligned}
& \lambda_{1}(T)=\left(\frac{\partial S}{\partial x}\right)_{* T}=-\omega_{1} \\
& \lambda_{2}(T)=\left(\frac{\partial S}{\partial y}\right)_{* T}=\omega_{2}
\end{aligned}
$$

Karena persamaan state dan costate memiliki bentuk non linier sehingga sulit untuk diselesaikan secara analitik maka diselesaikan secara numerik yaitu dengan metode forward backward sweep runge kutta orde 4 . Hal ini dilakukan karena persamaan statenya diketahui nilai awal dan persamaan costate diketahui nilai akhir (Resmi, Fitroh, \& Subchan, 2019).

Sebelum menyelesaikan masalah kendali optimal, pembahasan tentang sistem dinamik sebelum adanya kendali dilakukan terlebih dahulu. Hal ini bertujuan untuk dapat mengetahui ada tidaknya pengaruh kendali di dalam sistem tersebut. Dan juga akan dibahas pertumbuhan eceng gondok sebelum adanya ikan grass carp dengan adanya pemanenan dan tidak ada pemanenan. Berikut ini adalah nilai-nilai parameter yang digunakan:

Tabel 1. Nilai Parameter (Ilmiawan, et al, 2016)

\begin{tabular}{ccccccc}
\hline $\mathrm{r}$ & $\mathrm{K}$ & $\alpha$ & $\mathrm{m}$ & $e_{1}$ & $e_{2}$ & $\mathrm{a}$ \\
\hline 0,027 & 925 & 1 & 0,04 & 0,00038 & 0,02 & 2 \\
\hline
\end{tabular}

Laju pertumbuhan eceng gondok sebesar 0,027/minggu artinya setiap minggu pertumbuhan eceng gondok bertambah sebesar 2,7\% dari bobot biomassa sebelumnya. Kapasitas daya dukung 
lingkungan sebesar $925 \mathrm{~kg}$ artinya dalam suatu kolam dapat menampung eceng gondok sebesar 925 $\mathrm{kg}$. Laju pemangsaan ikan grass carp terhadap eceng gondok sebesar $1 /$ minggu artinya setiap minggu ikan grass carp dapat memangsa bobot eceng gondok sebesar 100\% dari bobot tubuhnya. Laju kematian sebesar 0,04/minggu artinya setiap minggu ada kematian ikan grass carp sebesar 4\% dari jumlah ikan grass carp di awal. Laju pemanenan eceng gondok $0,00038 /$ minggu artinya setiap minggu eceng gondok dipanen sebesar $0,038 \%$ dari bobot biomassa eceng gondok sebelumnya. Begitu juga untuk laju pemanenan ikan grass carp sebesar 0,02/minggu artinya setiap minggu $2 \%$ dari jumlah ikan grass carp di awal. Dan untuk tingkat kejenuhan ikan grass carp sebesar $2 \mathrm{~kg}$ artinya ketika ikan grass carp sudah memakan eceng gondok $2 \mathrm{~kg}$ dalam waktu seminggu maka ikan grass carp cenderung mencari makanan lain.

Selanjutnya akan dibahas pertumbuhan eceng gondok secara logistik tanpa adanya pemanenan. Dari Gambar 1 terlihat bahwa pertumbuhan eceng gondok terbatasi oleh kapasitas daya dukung sebesar $3 \mathrm{~kg}$. Sehingga eceng gondok dengan biomassa awal sebesar $2 \mathrm{~kg}$ akan tumbuh terus meningkat sampai pada minggu ke 68 kemudian pertumbuhannya tetap sebesar kapasitas daya dukungnya.

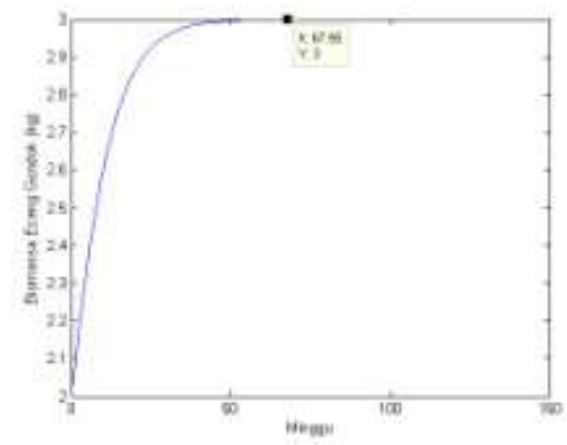

Gambar 1. Pertumbuhan logistik eceng gondok tanpa pemanenan

Selanjutnya akan dibahas pertumbuhan logistik eceng gondok dengan adanya pemanenan. Dengan nilai awal yang sama dan dengan laju pemanenan sebesar $0,038125 \mathrm{~kg}$ per minggu didapatkan penurunan biomassa eceng gondok jika dibandingkan dengan tidak adanya pemanenan. Pada Gambar 2 terlihat pada minggu ke 41 sampai minggu ke 150 biomassa eceng gondok stabil di $2,03 \mathrm{~kg}$. Jadi, dengan adanya pemanenan pertumbuhan eceng gondok hanya $0,03 \mathrm{~kg}$. Dalam hal ini pemanenan dapat menghambat laju pertumbuhan eceng gondok secara signifikan.

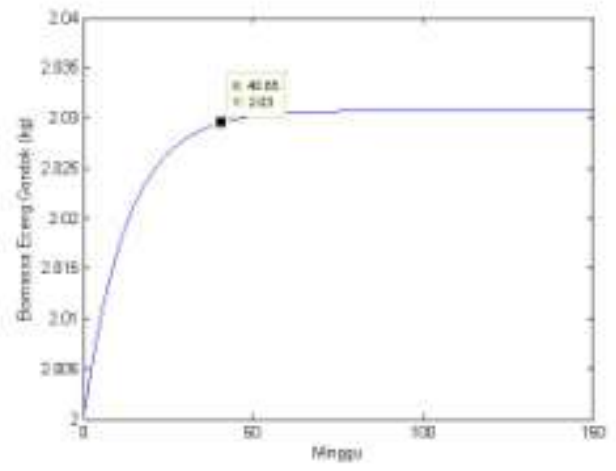

Gambar 2. Pertumbuhan Logistik Eceng Gondok dengan Pemanenan 
Namun, pemanenan membutuhkan usaha yang besar dan pertumbuhannya tetap mengalami kenaikan. Untuk itu dibuatlah kondisi adanya ikan grass carp dalam lingkungan tersebut. Dari hasil simulasi pada Gambar 3 didapatkan pertumbuhan eceng gondok mengalami penurunan yang cukup signifikan yaitu sebesar $1,6 \mathrm{~kg}$. Walaupun pada minggu ke 22 terdapat kenaikan sebesar $0,14 \mathrm{~kg}$, pertumbuhan eceng gondok stabil di 0,4 kg. Sedangkan pertumbuhan ikan grass carp mengalami kenaikan 1,6 kg sampai pada minggu ke 9. Kemudian terjadi penurunan dan stabil di 1,04 $\mathrm{kg}$. Walaupun begitu masih terdapat kenaikan biomassa ikan grass carp, yaitu dari biomassa awal 0,4 kg menjadi 1,04 kg. Sehingga walaupun tanpa pemanenan secara langsung terhadap eceng gondok, dengan adanya ikan grass carp dapat menekan pertumbuhan eceng gondok.
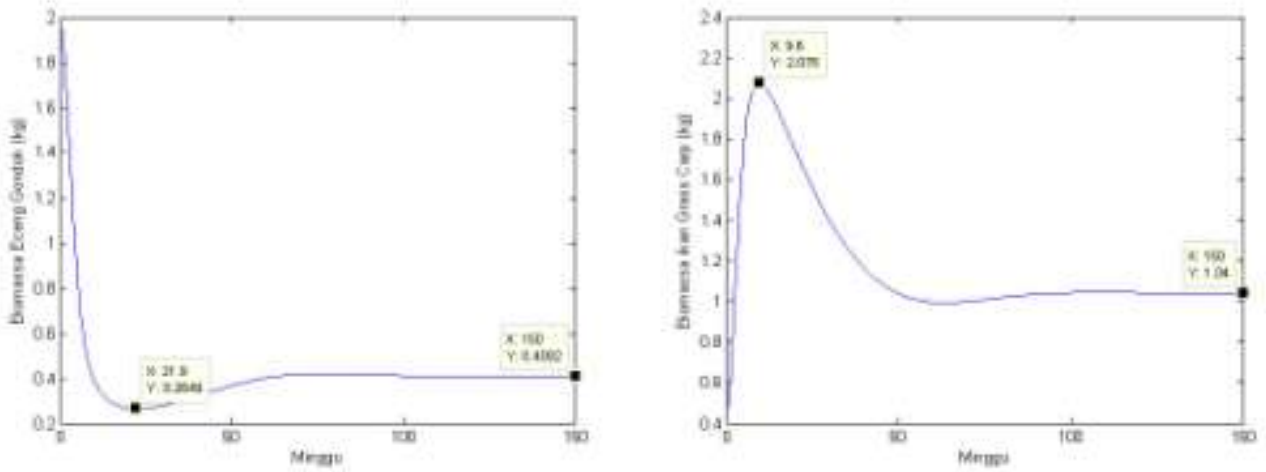

Gambar 3. Pertumbuhan eceng gondok dan ikan grass carp tanpa pemanenan keduanya

Selanjutnya diberikan faktor pemanenan terhadap ikan grass carp. Hal ini dilakukan agar sesuai dengan keadaan yang sebenarnya. Dimana masih ada kemungkinan pemancingan terhadap ikan grass carp, mengingat ikan grass carp memiliki daging yang lezat. Dengan laju pemanenan terhadap ikan grass carp sebesar 0,02 kg per minggu mengakibatkan biomassa eceng gondok di minggu ke 150 sebesar 0,5 kg dan biomassa ikan grass carp sebesar 0,8 kg. Jika dibandingkan dengan kondisi tanpa pemanenan, grafik pertumbuhan eceng gondok dan ikan grass carp dengan pemanenan memiliki kecenderungan hampir sama. Hanya saja terjadi kenaikan biomassa eceng gondok di waktu akhir. Hal ini terjadi karena jumlah ikan grass carp yang memakan eceng gondok berkurang. Dan tentunya penurunan biomassa ikan grass carp disebabkan oleh adanya pemanenan terhadap ikan grass carp. Hal ini dapat dilihat pada Gambar 4.
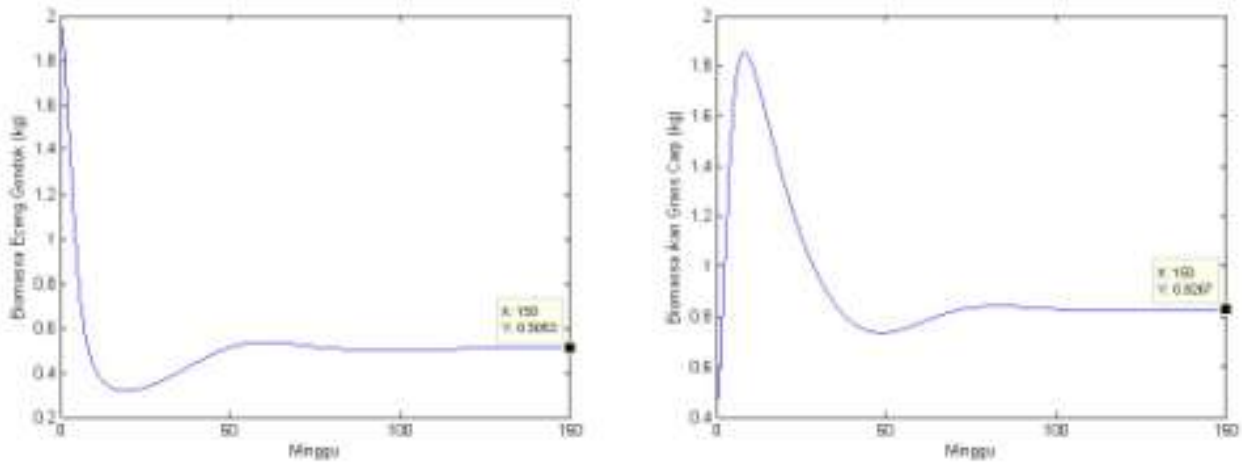

Gambar 4. Pertumbuhan eceng gondok dan ikan grass carp dengan pemanenan terhadap ikan grass carp 
Agar lebih optimal dalam mengendalikan pertumbuhan eceng gondok, maka dilakukan pemanenan terhadap eceng gondok dan juga tentunya pengadaan ikan grass carp. Pertumbuhan eceng gondok mengalami penurunan dari waktu ke waktu. Hingga minggu ke 150, pertumbuhannya stabil di 0,5 . Sedangkan pertumbuhan ikan grass carp mengalami kenaikan sampai minggu ke 8 . Setelah itu, pertumbuhannya menurun dan stabil di 0,5 . Untuk lebih jelasnya bisa dilihat di Gambar 5 .
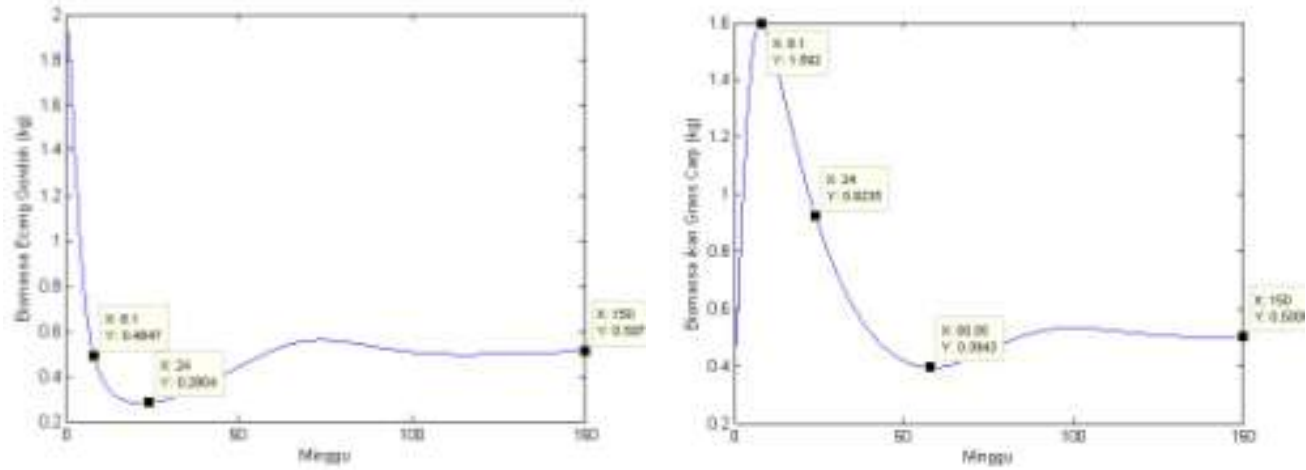

Gambar 5. Pertumbuhan eceng gondok dan ikan grass carp sebelum ada pengendalian

Jika dibandingkan dengan kondisi yang pemanenan hanya pada ikan grass carp (Gambar 4), Kondisi akhir biomassa eceng gondok tetap di $0,5 \mathrm{~kg}$, sedangkan kondisi akhir biomassa ikan grass carp mengalami penurunan $0,3 \mathrm{~kg}$ yaitu dari $0,8 \mathrm{~kg}$ menjadi $0,5 \mathrm{~kg}$. Maka pemanenan terhadap eceng gondok tidak secara optimal menurunkan biomassa eceng gondok bahkan menurunkan biomassa ikan grass carp.
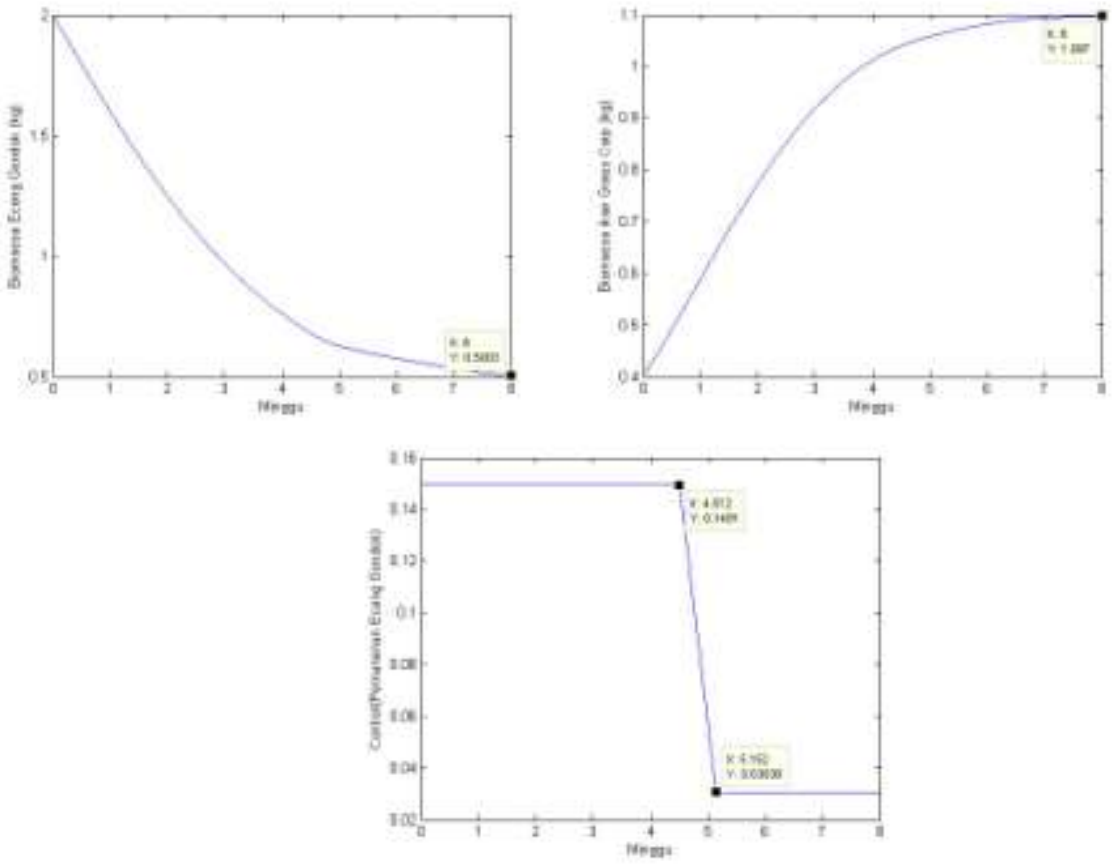

Gambar 6. Pertumbuhan eceng gondok dan ikan grass carp serta laju pemanenan eceng gondok 
Solusi lain yang dapat dilakukan adalah dengan menyelesaikan masalah kendali optimal. Dalam masalah kendali optimal dipilih bobot biomassa eceng gondok di waktu akhir, yaitu $w_{1}$ sebesar 1. Bobot biomassa ikan grass carp di waktu akhir, yaitu $w_{2}$ sebesar 1 . Sedangkan bobot fungsi biaya pemanenan selama waktu tertentu, yaitu $w_{3}$ sebesar 0.5 . Untuk batas minimal laju pemanenan sebesar $0,03 \mathrm{~kg} /$ minggu dan maksimal 0,02 kg/minggu.

Dari gambar 5 terlihat bahwa ikan grass carp mengalami kenaikan sampai pada minggu ke 8 dan eceng gondok mengalami penurunan sampai minggu ke 24 . Sehingga dalam menyelesaikan masalah kendali optimal dipilih waktu 8 minggu agar mengetahui seberapa besar pemanenan terhadap eceng gondok, dalam hal ini pemanenan eceng gondok menjadi kendalinya, agar pertumbuhan eceng gondok minimum di waktu akhir dan pertumbuhan ikan grass carp maksimum di waktu akhir. Dengan adanya kendali berupa laju pemanenan eceng gondok dapat meminimumkan biomassa eceng gondok dan memaksimumkan biomassa ikan grass carp di minggu ke-8 dengan laju pemanenan eceng gondok seperti pada gambar 6 , yaitu dari minggu pertama sampai minggu keempat eceng gondok diambil secara langsung sebesar $0,15 \mathrm{~kg} / \mathrm{minggu}$. Kemudian terdapat penurunan pemanenan sampai minggu kelima dan pemanenan konstan terjadi dari minggu kelima sampai minggu kedelapan sebesar 0,03 kg/minggu. Biomassa eceng gondok di minggu kedelapan dengan pengendalian ataupun tanpa pengendalian hasilnya tidak terlalu signifikan, masih samasama dapat menurunkan pertumbuhan eceng gondok, namun cukup signifikan terhadap pertumbuhan ikan grass carp.

\section{SIMPULAN}

Dalam kondisi lingkungan (sistem dinamik) yang hanya ada eceng gondok (tidak terdapat ikan grass carp), pertumbuhannya dapat dikendalikan dengan adanya pemanenan, walaupun pertumbuhannya masih meningkat tapi secara kuantitas jumlah biomassanya menurun. Dalam kondisi lingkungan yang sudah terkondisikan ada eceng gondok dan ikan grass carp, pertumbuhan eceng gondok dapat diturunkan walaupun sempat mengalami kenaikan tapi tidak terlalu signifikan.

Pertumbuhan Eceng Gondok masih dapat dikendalikan dengan adanya ikan grass carp walaupun ikan grass carp mengalami pemanenan. Begitu juga kondisi ketika pemanenan terhadap keduanya terjadi, pertumbuhan eceng gondok masih bisa diminimalkan. Hal yang sama juga terjadi ketika penerapan kendali optimal oleh pemanenan eceng gondok dilakukan. Pertumbuhan eceng gondok dapat diminimalkan walaupun biomassa ikan grass carp di waktu akhir tidak sebesar saat tanpa pengendalian. Sehingga pertumbuhan eceng gondok dapat dikendalikan dengan cara pemanenan dan penambahan ikan grass carp dalam lingkungannya.

\section{REFERENSI}

Ilmiawan, D.F., Carnawi, D.A., Novanda, V., Rifki, D.A., \& Muhammad, K. (2016). Analisis dinamik model Predator-Prey pada penyebaran grass carp fish sebagai biokontrol populasi eceng gondok di Perairan Rawapening. Journal of Creativity Students, Vol 1, No.1, April 2016.

Kementrian Kelautan dan Perikanan Balai Penelitian Perikanan Perairan Umum. (2014). Penelitian perikanan tangkap di Danau Kerinci Jambi.

Kementerian Lingkungan Hidup Republik Indonesia. (2014). Gerakan penyelamatan danau

(Germadan) Kerinci. Kementerian Lingkungan Hidup.

Naidu, S. D. (2002). Optimal control system. USA: CRC Press LLC. 
Naji'ah, E.F. \& Nurul, B . (2016). Pemanfaatan limbah eceng gondok berbasis pelatihan kontinum relation ship di Desa Kemlagi Lor Kecamatan Turi Kabupaten Lamongan. Jurnal Penelitian IImu Manajemen, Volume II No.2. Juni 2016.

Resmi, Fitroh, \& Subchan. (2019). Kendali optimal pada sistem Prey-Predator dengan pemberian makanan alternatif pada predator. Jurnal Matematics Paedagogic, Volume IV No.1, September 2019. 